\title{
Lubricity of bio-based lubricant derived from different chemically modified fatty acid methyl ester
}

\begin{abstract}
In this research, polyol ester was used as the source of a biolubricant. The trimethylolpropane (TMP) and pentaerythritol ester (PE) were produced from palm oil methyl ester; they are biodegradable and have high lubricity properties. Two different conditions of lubrication were investigated. Under these test conditions, the wear and friction characteristics of different ester samples were measured and compared. The esters derived from PE and TMP had comparable characteristics to the fully formulated lubricant (FFL) in terms of the coefficient of friction $(\mathrm{CoF})$. In terms of the mixed lubrication condition, the PE ester has the lowest CoF.
\end{abstract}

Keyword: Synthetic lubricant; Biolubricant; Tribology 